This paper has to be cited as: Dai K, Xu Q, Li Z, Tomás R, Fan X, Dong X, Li W, Zhou Z, Gou J and Ran P (2019) Post-disaster assessment of 2017 catastrophic xinmo landslide (china) by spaceborne sar interferometry. Landslides. doi: 10.1007/s10346-019-01152-4. The final publication is available at Springer via: https://link.springer.com/article/10.1007/s10346-019-01152-4

\title{
Post-disaster assessment of 2017 catastrophic Xinmo landslide (China) by spaceborne SAR interferometry
}

1. State Key Laboratory of Geohazard Prevention and Geoenviroment Protection, Chengdu University of Technology, Chengdu 610059, China;

2. State Key Laboratory of Geodesy and Earth's Dynamics, Institute of Geodesy and Geophysics, Chinese Academy of Sciences, Wuhan 430077, China;

3. College of Earth Sciences, Chengdu University of Technology, Chengdu 610059, China;

4. COMET, School of Engineering, Newcastle University, Newcastle upon Tyne NE1 7RU, UK;

5. Departamento de Ingeniería Civil, Escuela Politécnica Superior, Universidad de Alicante, P.O. Box 99, E-03080 Alicante, Spain

\section{* Corresponding author.xq@cdut.edu.cn}

Abstract: Timely and effective post-disaster assessment is of significance for the design of rescue plan, taking disaster mitigation measures and disaster analysis. Field investigation and remote sensing methods are the common way to perform post-disaster assessment, which are usually limited by dense cloud coverage, potential risk and tough transportation etc. in the mountainous area. In this paper, we employ the 2017 catastrophic Xinmo landslide (Sichuan, China) to demonstrate the feasibility of using spaceborne synthetic aperture radar (SAR) data to perform timely and effective postdisaster assessment. With C-band Sentinel-1 data, we propose to combine interferometric coherence to recognize the stable area, which helps us successfully identify landslide source area and boundaries in a space-based remote sensing way. Complementarily, X-band TanDEM-X SAR data allow us to generate a precise prefailure high-resolution digital elevation model (DEM), which provides us the ability to accurately estimate the depletion volume and accumulated volume of Xinmo landslide. The results prove that spaceborne SAR can provide a quick, valuable and unique assistance for post-disaster assessment of landslides from a space remote sensing way. 
This paper has to be cited as: Dai K, Xu Q, Li Z, Tomás R, Fan X, Dong X, Li W, Zhou Z, Gou J and Ran P (2019) Post-disaster assessment of 2017 catastrophic xinmo landslide (china) by spaceborne sar interferometry. Landslides. doi: 10.1007/s10346-019-01152-4. The final publication is available at Elsevier via: https://link.springer.com/article/10.1007/s10346-019-01152-4

At some conditions (bad weather, clouds, etc.) it can provide reliable alternative.

Keywords: post-disaster assessment; Xinmo landslide; InSAR; TanDEM-X; Sentinel1

\section{Introduction}

Xinmo landslide occurred at 5:38 a.m. on $24^{\text {th }}$ June 2017 (local time) in Xinmo village, Mao County, Sichuan Province in south-western China. In the early morning of that day, 64 homes in Xinmo village were buried by the massive rock avalanche with 10 people killed and 73 missing (Meng et al. 2018). Even though the transportation to Xinmo is tough and the landslide site is full of danger, the post-disaster assessment were performed immediately by field investigation from experts, such as locating the source area of the landslide, evaluating the possibility of reactivation or occurrence of new events and estimating the volume of the deposit mass. All of these post-disaster assessment work plays an important role in defining geometric features of the landslide to perform effective mitigation measures, to plan emergency responses and to support rescue tasks as well as for developing deeper analysis of the landslide (AnderssonSköld et al. 2013, Dai et al. 2002, Guzzetti et al. 1999).

Field investigation is the direct way to assess the landslide after the failure. However, the damaged transportation, potential risk and weather condition usually limited the field investigation by human. In addition, as the source area of Xinmo landslide was located at high elevation, it is difficult for researchers to acquire information on the head and the crown when arriving at the foot of the landslide (Fan et al. 2017). In this regard, remote sensing is an effective way to provide comprehensive information for post-disaster assessment, such as land-cover changes and fissure detection (e.g. Tsai et al. 2010). Fan et al. (2017a) and Fan et al. (2017b) performed the disaster assessment of Xinmo landslide based on remote sensing data including QuickBird, Pleiades-1 and GF-2 images acquired several days after the landslide. In this case the optical remote sensing data are prone to be affected by dense cloud coverage in the mountainous area and usually only qualitative visual interpretation can be performed.

Interferometric synthetic aperture radar (InSAR) has been developed into a powerful earth observation technology to estimate the height of the Earth surface (Dai et al. 2016, 
This paper has to be cited as: Dai K, Xu Q, Li Z, Tomás R, Fan X, Dong X, Li W, Zhou Z, Gou J and Ran P (2019) Post-disaster assessment of 2017 catastrophic xinmo landslide (china) by spaceborne sar interferometry. Landslides. doi: 10.1007/s10346-019-01152-4. The final publication is available at Elsevier via: https://link.springer.com/article/10.1007/s10346-019-01152-4

Du et al. 2017, Ferretti et al. 1999, Gao et al. 2017, Neelmeijer et al. 2017) and detect land deformation (Chen et al. 2016, Dai et al. 2015, Ge et al. 2014, Miller et al. 2015, Van der Horst et al. 2018). InSAR presents a large number of features such as independence of weather conditions, high accuracy and wide spatial coverage. Slope activity displacements monitored by InSAR were widely studied during the last few years (e.g. Cigna et al. 2013, Colesanti et al. 2006, Cascini et al. 2010, Frattini et al. 2018, Intrieri et al. 2017, Qu et al. 2016, Raspini et al. 2015, Shi et al. 2018, Tomás et al. 2015). Due to the revisiting time of SAR acquisitions and the measuring object, the ability of spaceborne InSAR to acquire useful information for prompt post-failure assessment and rescue work remains to be exploited.

In this paper, we illustrate the utility and ability of spaceborne microwave SAR data to perform post-disaster assessment of Xinmo landslide. Even though the landslide body will loss coherence during the failure and cannot be measured by InSAR techniques, we propose to use interferometric coherence analysis to recognize the stable area, which is helpful for us to successfully identify landslide source area and boundaries with Cband Sentinel-1 data. In addition, we used TerraSAR-X/TanDEM-X data to acquire the up-to-date high-resolution pre-failure digital elevation model (DEM). Compared with the post-failure DEM derived from unmanned aerial vehicle (UAV), the volume of Xinmo landslide was derived, providing an accurate volume estimation. This case study illustrates SAR data can provide valuable and unique information for the assistance of timely and effective post-failure landslide assessment, complementing conventional in situ techniques from a space remote sensing way. It can be used as an alternative if use of the "conventional" methods is impossible.

\section{Geological settings and data sets used in this study}

\subsection{Location and geological settings}

The Xinmo village was located in a mountainous region of the western Sichuan province, China (Fig. 1a), $200 \mathrm{~km}$ away from Chengdu (the capital city of Sichuan) and $70 \mathrm{~km}$ from Wenchuan (Fig. 2a). The area is located at the eastern margin of the Qinghai-Tibetan Plateau (Zhao et al. 2018). This region is a very active seismic area in 
This paper has to be cited as: Dai K, Xu Q, Li Z, Tomás R, Fan X, Dong X, Li W, Zhou Z, Gou J and Ran P (2019) Post-disaster assessment of 2017 catastrophic xinmo landslide (china) by spaceborne sar interferometry. Landslides. doi: 10.1007/s10346-019-01152-4. The final publication is available at Elsevier via: https://link.springer.com/article/10.1007/s10346-019-01152-4

which three major earthquakes were recorded since 1930s, namely the $1933 \mathrm{Mw} 7.3$ Diexi earthquake, the 1976 Mw 6.7 Songpan-Pingwu earthquake and the $2008 \mathrm{Mw} 7.9$ Wenchuan earthquake. In the area, a North-West trending fault (i.e. Songpinggou Fault) intersects the middle part of Xinmo landslide and the preexisting old landslide deposits (Fig. 1b; ( $\mathrm{Hu}$ et al. 2018)). Metamorphic sandstones, marbleized limestones and phyllites belonging to the Weiguanqun formation of the Lower Permian $\left(\mathrm{P}_{1}\right)$ period and to the Bocigou ( $\left.\mathrm{T}_{1 \mathrm{~b}}\right)$ and the Zagunao $\left(\mathrm{T}_{2 \mathrm{z}}\right)$ formations of the Triassic, as well as Quaternary lacustrine (Q) and recent rock avalanches deposits, outcrop in the study area (Fan et al. 2017).

The landslide was developed in a bedding-controlled high steep slope with an altitude of $3470 \mathrm{~m}$ a.s.1. in which the strata and the aspect of the slope are practically coincident. The slope is composed of interbedded metamorphic sandstone and thin slate ( $\mathrm{T}_{2 \mathrm{z}}$ in Fig. $1 \mathrm{~b}$ and $1 \mathrm{c}$ ) with an attitude $\mathrm{N} 80^{\circ} \mathrm{W} / 47^{\circ} \mathrm{SW}$ (Pei et al. 2018). It was placed on the same site of a coseismic landslide triggered by the Mw 7.3 Diexi earthquake in 1933 (Scaringi et al. 2018). The well-exposed Xinmo village section was about $11 \mathrm{~m}$ thick and mostly composed of grayish clay, silty clay and clayey silt with massive structure and horizontal bedding (Jiang et al. 2014). The mean annual temperature at Mao County is $11.2^{\circ} \mathrm{C}$ and the mean annual precipitation is $490.7 \mathrm{~mm}$, with $70-90 \%$ of the precipitation falling from June to September (Jiang et al. 2014). The detailed geological settings were already presented by several previous papers (Dong et al. 2017, Fan et al. 2017a, Fan et al. 2017b, Intrieri et al. 2017, Qiu et al. 2017, Su et al. 2017, Wang et al. 2017). 
This paper has to be cited as: Dai K, Xu Q, Li Z, Tomás R, Fan X, Dong X, Li W, Zhou Z, Gou J and Ran P (2019) Post-disaster assessment of 2017 catastrophic xinmo landslide (china) by spaceborne sar interferometry. Landslides. doi: 10.1007/s10346-019-01152-4. The final publication is available at Elsevier via: https://link.springer.com/article/10.1007/s10346-019-01152-4

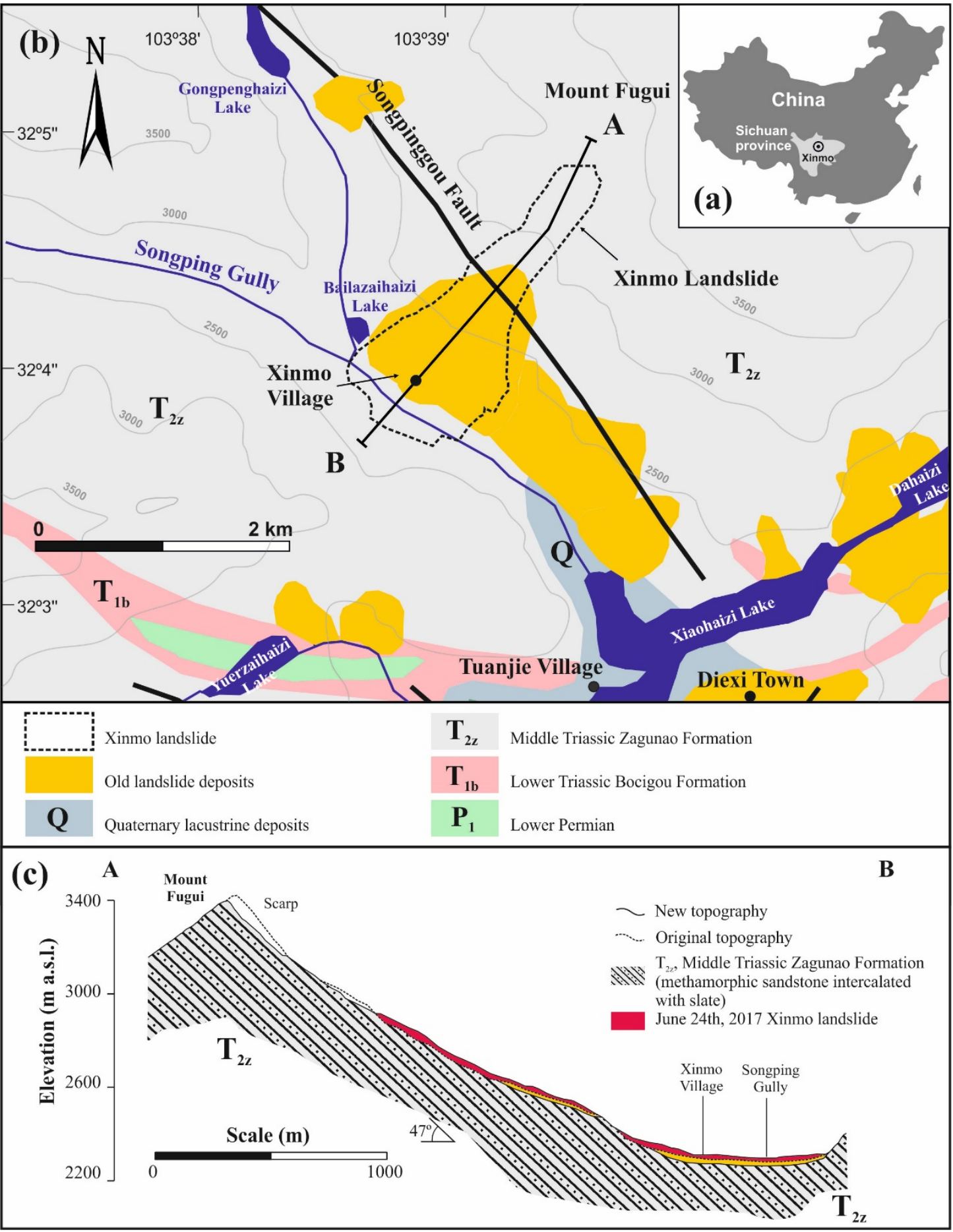

111 Fig. 1 (a) Location of the study area; (b) Geological map of the study region; (c) Geological cross section of the Xinmo landslide (based on Fan et al. 2017b) 
This paper has to be cited as: Dai K, Xu Q, Li Z, Tomás R, Fan X, Dong X, Li W, Zhou Z, Gou J and Ran P (2019) Post-disaster assessment of 2017 catastrophic xinmo landslide (china) by spaceborne sar interferometry. Landslides. doi: 10.1007/s10346-019-01152-4. The final publication is available at Elsevier via: https://link.springer.com/article/10.1007/s10346-019-01152-4

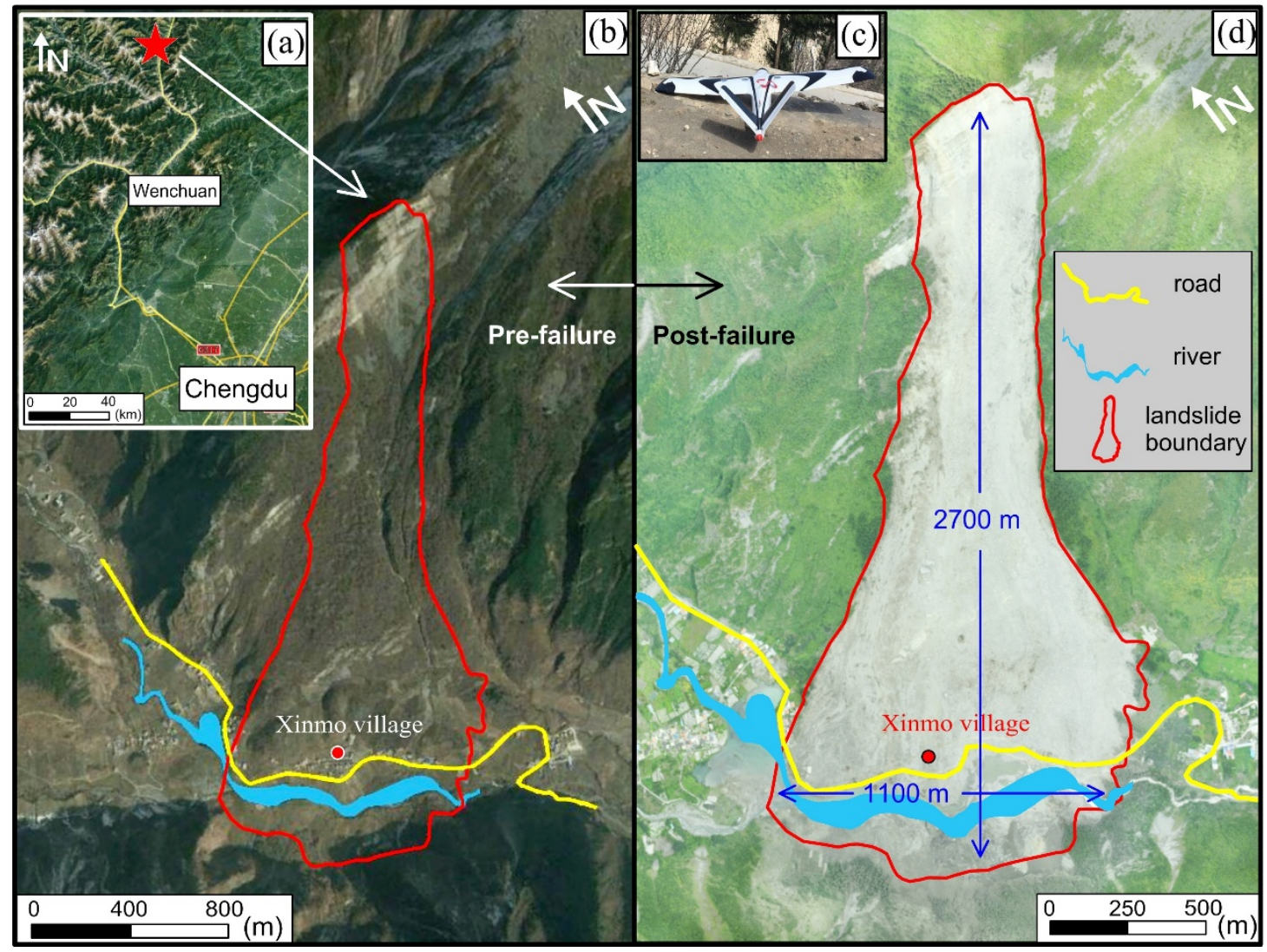

114 Fig. 2 (a) Location of Xinmo landslide. (b) Pre-failure image of Xinmo landslide from Google earth. (c) The Feima F1000 UAV used in this study. (d) Post-failure UAV image of Xinmo 116 landslide.

117 The landslide body with maximal length and width of 2700 and $110 \mathrm{~m}$ respectively 118 fully buried the Xinmo village (Fig. 2d). The preliminary results suggest that the 119 landslide was triggered by the failure of a rock mass, which had already been weakened 120 by the Mw 7.3 Diexi earthquake in 1933 (Fan et al. 2017b). Under several strong 121 seismic activities, the rock mass was damaged due to the discordant deformation from 122 existing different lithology (Pei et al. 2018). Weathering of the rock mass also played 123 an important role in the potential fracturing of the rock mass (Hu et al. 2018), causing 124 the existing cracks wider and "weaker". In addition, the failure time of this landslide 125 (24th, June) was in the begging of the rainy season, after one week of continuous 126 rainfall. Therefore, multi-factors including the several major earthquakes, the rock mass 127 weathering, the long-term effect of gravity and rainfall, contributed to the mass failure, 128 resulting in death of more than 80 people. 
This paper has to be cited as: Dai K, Xu Q, Li Z, Tomás R, Fan X, Dong X, Li W, Zhou Z, Gou J and Ran P (2019) Post-disaster assessment of 2017 catastrophic xinmo landslide (china) by spaceborne sar interferometry. Landslides. doi: 10.1007/s10346-019-01152-4. The final publication is available at Elsevier via:

\subsection{Data used in this study}

Table 1 lists all the data used in this study, in which the dashed line denotes the failure time of Xinmo landslide (i.e. $24^{\text {th }}$ June 2017). The pre-failure and post-failure SAR data were acquired by ESA's (European Space Agency) Sentinel-1A satellite in ascending orbit. The Sentinel-1 satellite operates day and night performing C-band synthetic aperture radar imaging, providing us imagery regardless of the weather with a wide coverage $(250 \times 250 \mathrm{~km})$ and a short repeat cycle ( 6 days for the constellation, 12 days for a single satellite) (ESA 2014). It should be noted that the image 20170624 was acquired just 13 hours after the landslide as the first post-failure SAR image.

The TerraSAR-X/TanDEM-X SAR image covering Xinmo area was acquired on 07 February 2017 by the TerraSAR-X/TanDEM-X satellites from German Aerospace Center (DLR), which could be used to acquire the high-resolution pre-failure DEM. TerraSAR-X/TanDEM-X is the first bistatic SAR mission, formed by adding a second, almost identical spacecraft (i.e. TanDEM-X) to TerraSAR-X and flying the two satellites in a closely controlled formation with typical distances between 250 and 500 m (DLR 2010).

Table $1 \mathrm{SAR}$ and UAV data used in this study near the failure time of Xinmo landslide (denoted by dashed line below).

\begin{tabular}{|c|c|c|c|}
\hline \multicolumn{2}{|c|}{ Acquisition Date } & Data Types & Source \\
\hline \multirow{2}{*}{ 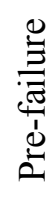 } & 20170207 & SAR data & TerraSAR-X/TanDEM-X \\
\hline & 20170612 & SAR data & Sentinel-1A \\
\hline \multirow{2}{*}{$\begin{array}{l}\stackrel{0}{\Xi} \\
: \frac{\pi}{4} \\
\frac{1}{0} \\
0\end{array}$} & 20170624 & SAR data & Sentinel-1A \\
\hline & 20170626 & UAV image & by SKLGP \\
\hline
\end{tabular}
UAV surveying is a time-saving, effective and safe way for obtaining DEM in mountainous areas compared with other traditional land survey. In the last few years, aerial photogrammetry by UAV has been widely used in landslide investigation. This 
This paper has to be cited as: Dai K, Xu Q, Li Z, Tomás R, Fan X, Dong X, Li W, Zhou Z, Gou J and Ran P (2019) Post-disaster assessment of 2017 catastrophic xinmo landslide (china) by spaceborne sar interferometry. Landslides. doi: 10.1007/s10346-019-01152-4. The final publication is available at Elsevier via: https://link.springer.com/article/10.1007/s10346-019-01152-4

151 with multi-temporal aerial and UAV photograph (e.g. Lucieer, et al. 2014; Fernández et 152 al. 2017; Del Soldato et al. 2018; Rossi et al. 2018). As fast as we can, two days after 153 the landslide (i.e. on $26^{\text {th }}$ June, 2017), the UAV image was acquired by the State Key 154 Laboratory of Geohazard Prevention and Geoenviroment Protection (SKLGP) based in 155 Chengdu University of Technology (China). The aircraft used in this study was the 156 Feima Intelligent Aerial Survey System F1000 (Fig. 2c) from Feima Robotics Company. 157 The maximum duration of one flight is 1.5 hour with a takeoff weight of $3.2 \mathrm{~kg}$. The post-failure photos were acquired with a Sony a 5100 digital camera and E20MM-F2.8 lens aboard this UAV, in which the landslide boundary and the whole buried Xinmo

160 village can be easily identified (Fig. 2d).

\section{3. Methodology}

\subsection{Coherence analysis}

163 SAR image pairs, acquired before and after events such as landslides, earthquakes or volcanoes, would lose coherence to some degree due to the 'big' movement during the event. With pre-failure and post-failure SAR images, theoretically the landslide body will lose coherence and cannot be measured by InSAR (Colesanti et al. 2006). In some case such interferometric pair are regarded as useless pair because the area with movement are totally decoherent and the movement cannot be measured. Furthermore, apart from big movements, several other factors would cause decoherent, such as vegetation on the slope. It means that decoherence information cannot perfectly

171 delineate the boundary of landslide.

172 On the other hand, the area without movement will keep coherence during the time span

173 of the interferometric pair. In other words, the area with good coherence must imply the 174 stability of this area (no big movement). Based on this characteristic, we can use 175 interferometric pairs spanning the event time (i.e. images acquired before and after 176 landslide) to map the landslide boundary.

177 The correlation coefficient $(\gamma)$ at a pixel can be calculated within a selected $m \times n$ pixels

178 window (e.g. $5 \times 5$ has been used in this study) according to next equation (Hanssen 179 2000), 
This paper has to be cited as: Dai K, Xu Q, Li Z, Tomás R, Fan X, Dong X, Li W, Zhou Z, Gou J and Ran P (2019) Post-disaster assessment of 2017 catastrophic xinmo landslide (china) by spaceborne sar interferometry. Landslides. doi: 10.1007/s10346-019-01152-4. The final publication is available at Elsevier via:

$$
\gamma=\frac{\left|\sum_{i=1}^{m} \sum_{j=1}^{n} M(i, j) \otimes S(i, j)\right|}{\sqrt{\sum_{i=1}^{m} \sum_{j=1}^{n}|M(i, j)|^{2} \sum_{i=1}^{m} \sum_{j=1}^{n}|N(i, j)|^{2}}}
$$

$\mathrm{M}(i, j)$ and $\mathrm{S}(i, j)$ are the complex value on the pixel $(i, j)$ at master and slave image, respectively. $\otimes$ denotes conjugate multiplication. After the filter processing, in the interferograms the pixels with correlation coefficient less than a threshold will be masked out and only the pixels with high correlation coefficient will be kept. Thus we can derive the area with high coherence, which can be regarded as stable area. This whole flowchart was shown in Fig. 3 Coherence analysis.

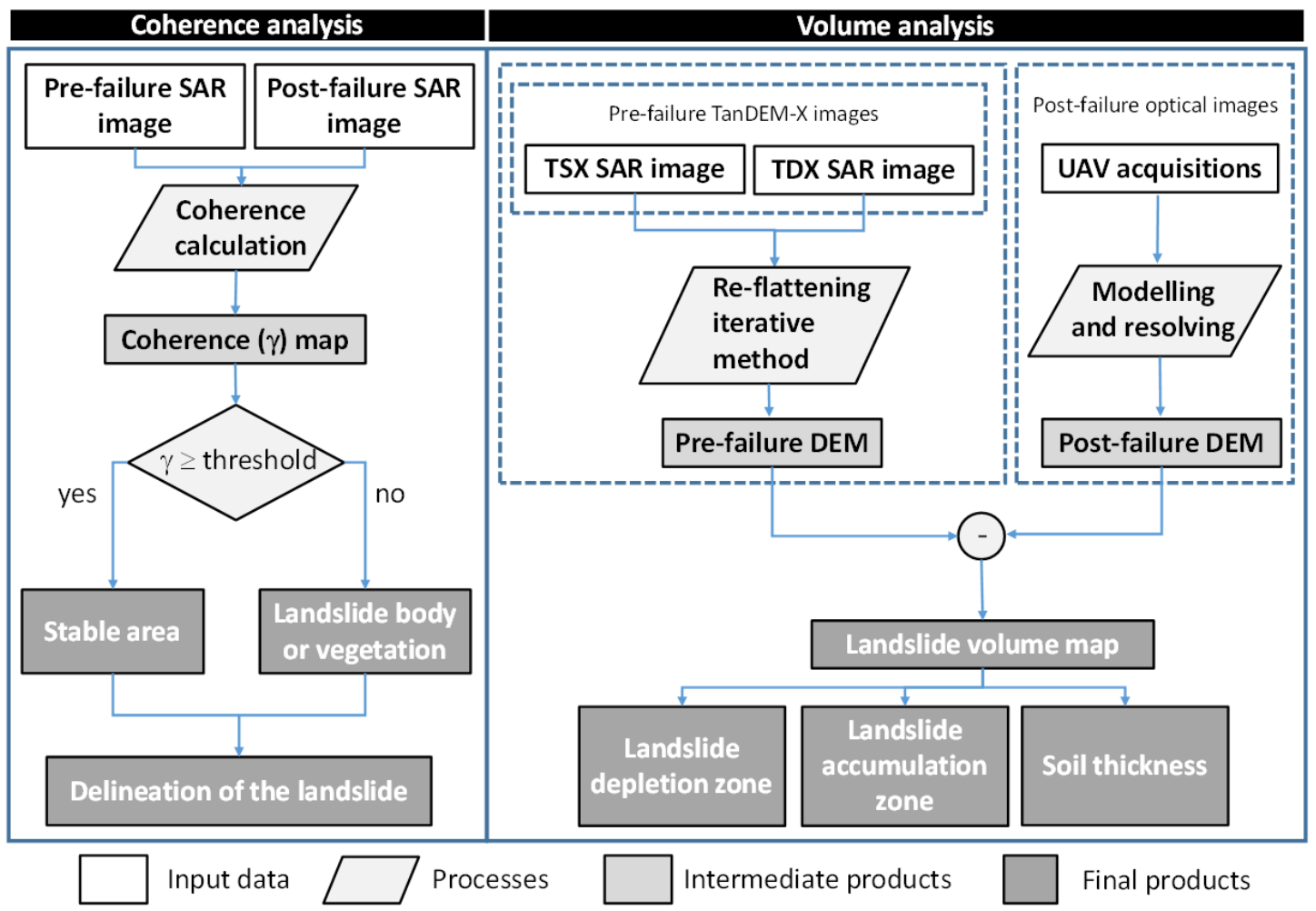

Fig. 3 The summary figure and explanation on the methodology from a landslide final user's 189 point of view.

\subsection{Volume analysis}

191 The landslide volume estimation is a necessary work to define geometrical features of

192 the landslide, to plan suitable emergency responses and to support rescue tasks. The

193 landslide accumulation volume is usually estimated by some empirical statistical model 
This paper has to be cited as: Dai K, Xu Q, Li Z, Tomás R, Fan X, Dong X, Li W, Zhou Z, Gou J and Ran P (2019) Post-disaster assessment of 2017 catastrophic xinmo landslide (china) by spaceborne sar interferometry. Landslides. doi: 10.1007/s10346-019-01152-4. The final publication is available at Elsevier via: https://link.springer.com/article/10.1007/s10346-019-01152-4

194 (e.g. Fan et al. 2012, Fiorucci et al. 2011) using the affected area and the thickness information with coarse accuracy. With the fast development of survey technique, the precise post-failure DEM can be easily acquired through UAV photogrammetry. How to acquire the accurate and up-to-date pre-failure DEM was the key to perform a precise volume estimation. The commonly wide used DEM in Sichuan is the SRTM with $30 \mathrm{~m}$ spatial resolution and less than $15 \mathrm{~m}$ vertical accuracy, which cannot meet the requirement for precise volume estimation.

201 In this study, we acquired the pre-failure DEM by means of InSAR with the TanDEM-

$202 \mathrm{X}$ data, which was acquired four months before the landslide. Considering the low 203 coherence and high topographic gradients in the mountainous area, the re-flattening 204 iterative method (Dai et al. 2016) was used to acquire a high accuracy DEM. The 205 flowchart of this method is shown in Fig. 4, and the details were presented as following.

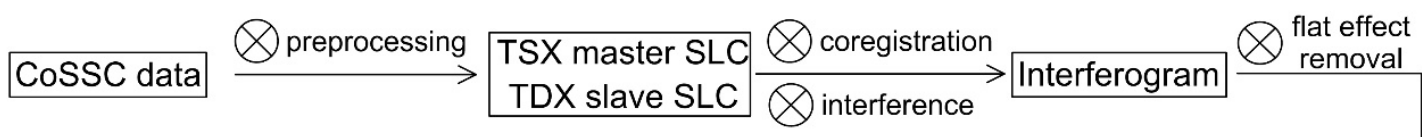
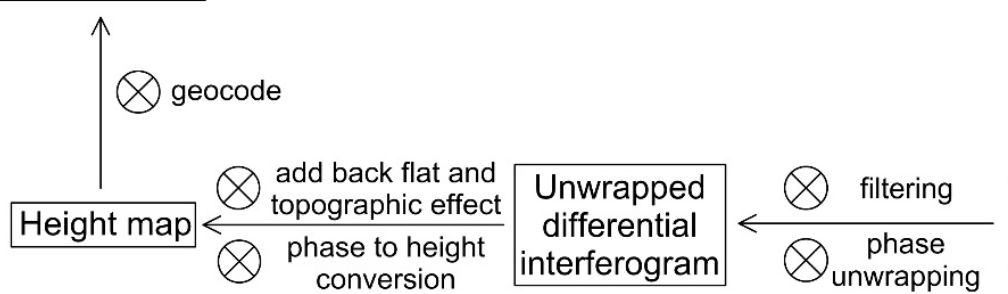

\section{Differential} interferogram

207 Fig. 4 Flowchart of re-flattening iterative method (Dai et al. 2016) for DEM generation.

208 The TanDEM-X data described in section 2.2 were acquired in coregistered single-look 209 slant-range complex (CoSSC) format. After preprocessing, two images in Single Look

210 Complex (SLC) format were acquired, in which the image from TerraSAR-X satellite 211 was called TSX master SLC and the image from TanDEM-X satellite was called TDX 212 slave SLC. With precise orbit information, 'flat effect' was removed from the 213 interferograms generated by the coregistration and interference between the two SLCs. 214 In the first iteration, the external DEM such as SRTM data could be used to remove the 215 topographic effect to acquire differential interferogram. The flat and topographic effect 
This paper has to be cited as: Dai K, Xu Q, Li Z, Tomás R, Fan X, Dong X, Li W, Zhou Z, Gou J and Ran P (2019) Post-disaster assessment of 2017 catastrophic xinmo landslide (china) by spaceborne sar interferometry. Landslides. doi: 10.1007/s10346-019-01152-4. The final publication is available at Elsevier via: https://link.springer.com/article/10.1007/s10346-019-01152-4

216 were added back to unwrapped differential interferogram which was generated after 217 filtering and phase unwrapping processing. The phase at this stage will be converted to 218 height with the precise orbit estimation. After geocoding, the DEM product will be 219 generated and used to re-flatten the original interferograms, and the processing will be 220 performed again to get the $2^{\text {nd }}$ DEM product until no topography dependent residual 221 fringe is observed in the re-flattened differential interferogram. The details of this 222 method could be found on (Dai et al. 2016).

223 With the pre-failure TanDEM-X DEM and post-failure UAV DEM, the landslide 224 volume map can be acquired. As shown in Fig. 3 volume analysis, based on this volume 225 map then we can derive the volume of landslide depletion and accumulation zones, as 226 well as the spatial distribution of the soil thickness. 
This paper has to be cited as: Dai K, Xu Q, Li Z, Tomás R, Fan X, Dong X, Li W, Zhou Z, Gou J and Ran P (2019) Post-disaster assessment of 2017 catastrophic xinmo landslide (china) by spaceborne sar interferometry. Landslides. doi: 10.1007/s10346-019-01152-4. The final publication is available at Elsevier via:

https://ink.springer.com/article/10.1007/s10346-019-01152-4

\section{Identify landslide source area and boundaries assisted with InSAR}

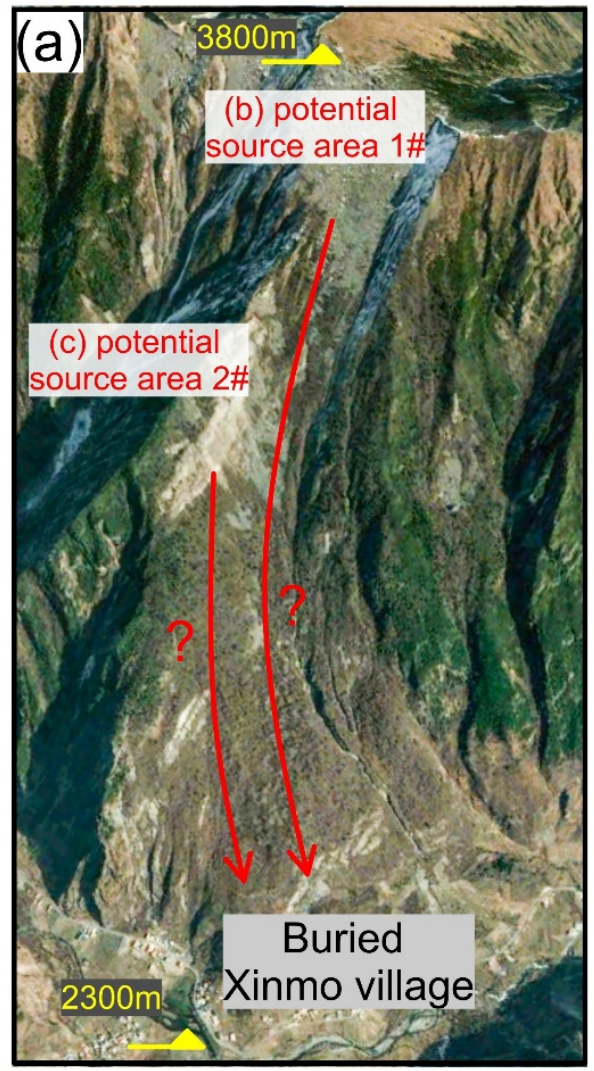

failure at

(d) on-site photo
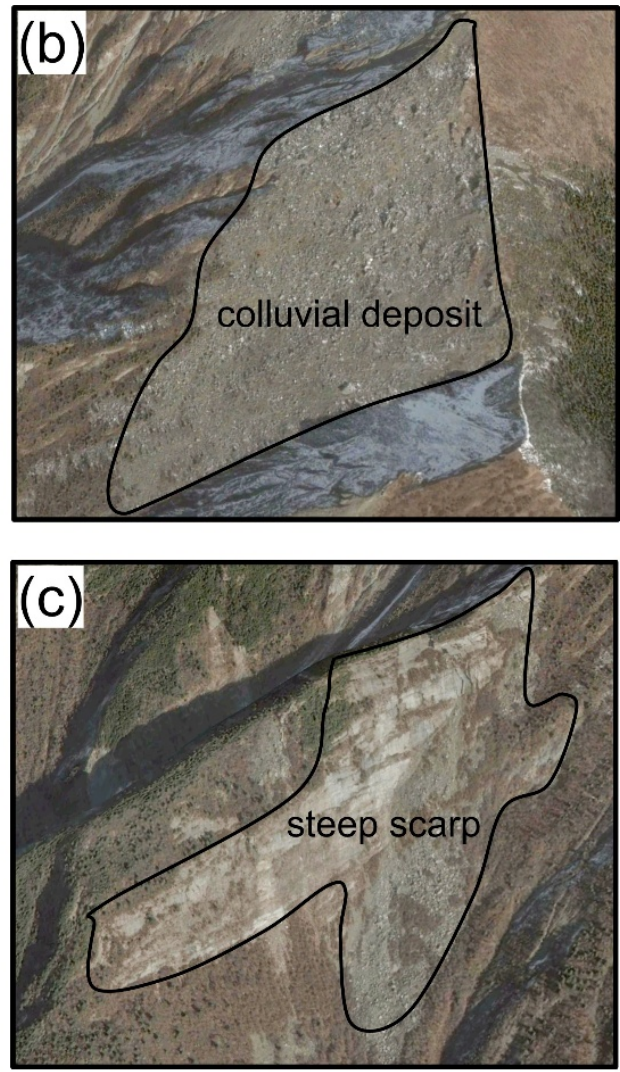

2017/06/24 05:38 2017/06/24 16:07
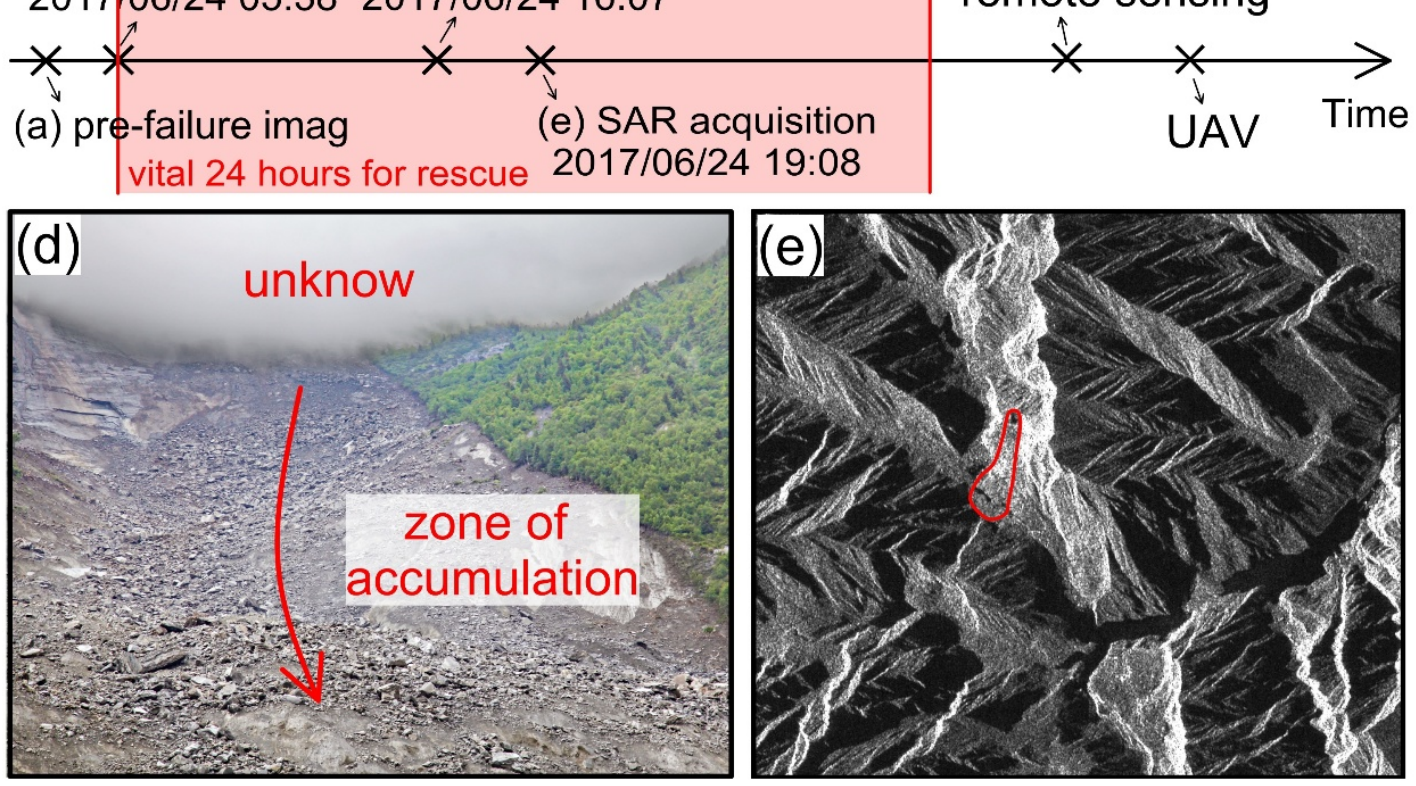

Fig. 5 Timeline of each acquisition after the failure of Xinmo landslide. (a) Pre-failure optical satellite image and two potential source areas were inferred; Google earth image of potential 
This paper has to be cited as: Dai K, Xu Q, Li Z, Tomás R, Fan X, Dong X, Li W, Zhou Z, Gou J and Ran P (2019) Post-disaster assessment of 2017 catastrophic xinmo landslide (china) by spaceborne sar interferometry. Landslides. doi: 10.1007/s10346-019-01152-4. The final publication is available at Elsevier via: https://link.springer.com/article/10.1007/s10346-019-01152-4

source areas 1\#(b) and 2\# (c); (d) on-site photo taken on 2017/06/24 16:07; (e) Sentinel-1 SAR image acquired on 2017/06/24 19:08.

233 After the failure of Xinmo landslide on 2017/06/24 05:38, the whole Xinmo village was 234 buried under the landslide mass. The immediate post-disaster assessment is of paramount importance to guide the rescue operation, not only for rescuing the buried people, but also for ensuring the live safety of rescue workers. Based on the archived satellite optical remote sensing data, two potential source areas were recognized (Fig. $5 \mathrm{a}, 5 \mathrm{~b}$ and $5 \mathrm{c}$ ). The difference of the source area would have big effect on the preliminary volume estimation and secondary collapse evaluation. The relevant experts went to Xinmo immediately and on-site photos were acquired on 2017/06/24 16:07 (Fig. 5d). However, in this case due to the dense cloud weather condition and steep terrain, 242 the source area could not be identified by on-site investigation or UAV to evaluate the 243 possibility of occurrence of a potential secondary collapse.

244 Fortunately, one SAR image was acquired by Sentinel-1 with ascending orbit on 245 2017/06/24 19:08. With one pre-failure Sentinel-1 acquisition on 2017/06/12, the 246 interferogram 20170612-20170624 was generated with about one hour processing time 247 and the low coherence pixels (i.e. those with a coherence lower than 0.5) were masked 248 out (Fig. 6a). The areas with interferometric phase (i.e. area with high coherence) were regarded as stable areas because they can keep coherence during the failure of landslide.

250 Buildings and the river near Xinmo village were marked with orange polygon and blue 251 polygon, respectively. As shown in Fig. 6, the location of the accumulated mass was 252 known according to the news and field investigation. Even though the displacements of 253 the landslide body cannot be measured by InSAR due to the 'big' movement magnitude, 254 based on the location of the stable area and accumulated mass, the source area (zone of 255 depletion) can be inferred and marked with green dash circle, respectively (Fig. 6). It 256 can be concluded that the source area were not from the highest part of this big slope 257 (potential source area 1\# in Fig. 5a and 5b), while it is from the potential source area 258 2\# in Fig. 5a and 5c (green dash circle in Fig. 6).

259 From the stable area in this interferogram, the left and right boundaries of the landslide 260 accumulated material could be constrained by the stable areas, which play an important 261 role in the early recognition of the landslide boundaries. On 26 June 2017, two days 
This paper has to be cited as: Dai K, Xu Q, Li Z, Tomás R, Fan X, Dong X, Li W, Zhou Z, Gou J and Ran P (2019) Post-disaster assessment of 2017 catastrophic xinmo landslide (china) by spaceborne sar interferometry. Landslides. doi: 10.1007/s10346-019-01152-4. The final publication is available at Elsevier via: https://link.springer.com/article/10.1007/s10346-019-01152-4

262 after the failure, the UAV image was acquired, shown in Fig. 7 with simple 263 interpretation including the actual source area, landslide body, the river and buildings. 264 An area at the zone of accumulation (black rectangle area in Fig. 6 and Fig. 7a) was 265 zoomed in Fig. $7 \mathrm{~b}$ and $7 \mathrm{c}$. We can deduce from Fig. $7 \mathrm{~b}$ that the inferred landslide 266 boundary (red dash line) would close to the stable area and covered the pond as there 267 was no pond found on site. For the comparison purpose, the interpretation result of the 268 same area from UAV was shown in Fig. 7c. It is clear that the actual boundary line (red 269 line) are in the same location between stable area and the buried pond, which shows a 270 good agreement between InSAR coherence analysis and the actual situation.

271 Therefore, from this case we can see that the first Sentinel-1 interferogram (acquired

27213 hours after the failure), together with its corresponding coherence maps, not only 273 helped us identify the source area of this massive landslide, but also assisted with 274 mapping the landslide boundary (COMET 2017), proving that InSAR could be an 275 effective and alternative way to perform timely and precise post disaster assessment 276 under some specific tough condition (e.g. cloudy weather condition and steep terrain). 
This paper has to be cited as: Dai K, Xu Q, Li Z, Tomás R, Fan X, Dong X, Li W, Zhou Z, Gou J and Ran P (2019) Post-disaster assessment of 2017 catastrophic xinmo landslide (china) by spaceborne sar interferometry. Landslides. doi: 10.1007/s10346-019-01152-4. The final publication is available at Elsevier via:

https://ink.springer.com/article/10.1007/s10346-019-01152-4

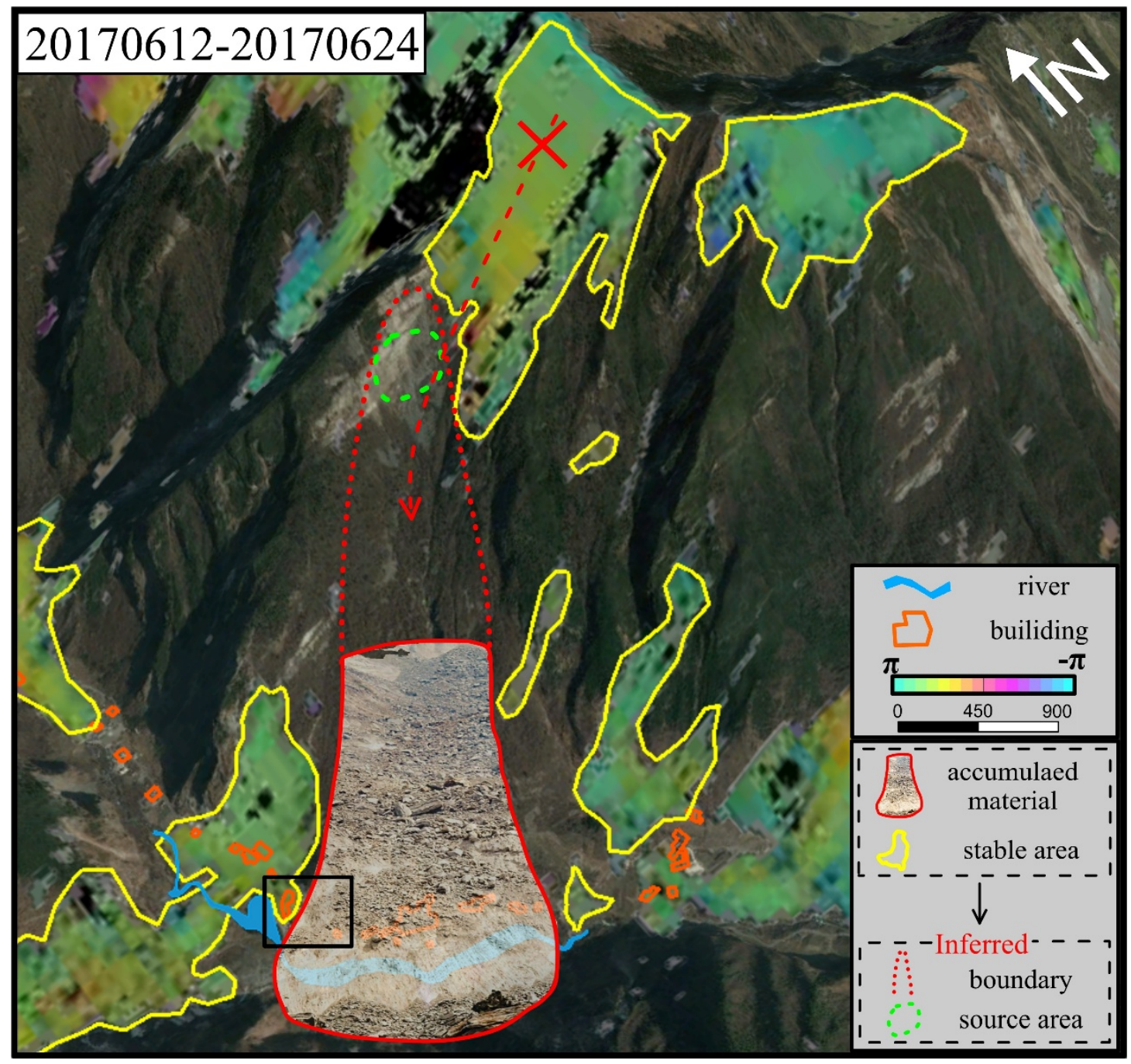

278 Fig. 6 Interferogram 20170612-20170624 with coherence analysis. Black rectangle area was

279 enlarged shown in Fig. 7b. The red dashed arrow and the red cross indicate the potential run-out

280 trajectory of the landslide and the potential source area, which can be excluded by coherence 281 analysis. 
This paper has to be cited as: Dai K, Xu Q, Li Z, Tomás R, Fan X, Dong X, Li W, Zhou Z, Gou J and Ran P (2019) Post-disaster assessment of 2017 catastrophic xinmo landslide (china) by spaceborne sar interferometry. Landslides. doi: 10.1007/s10346-019-01152-4. The final publication is available at Elsevier via: https://ink.springer.com/article/10.1007/s10346-019-01152-4
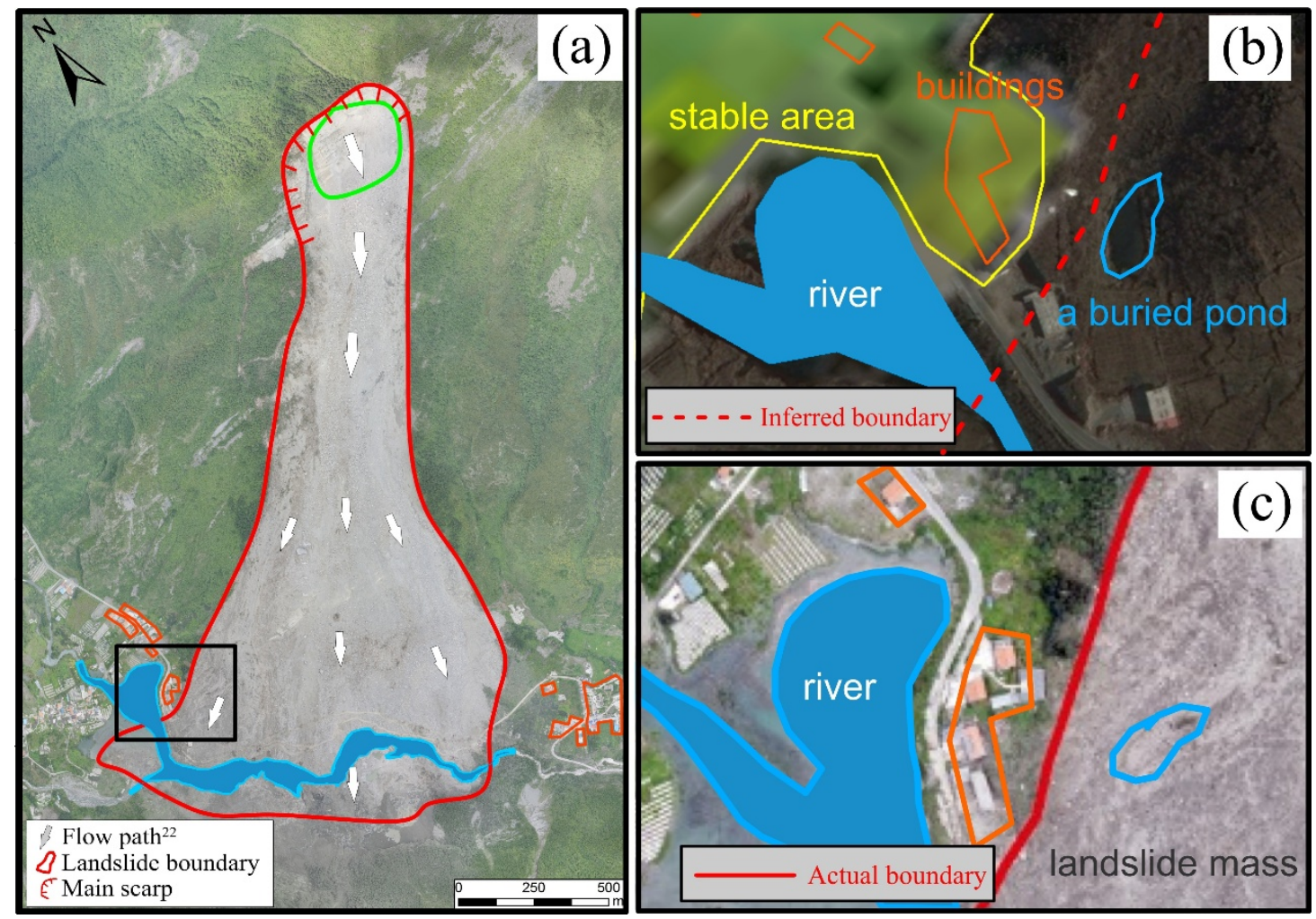

283 Fig. 7 (a) UAV image with simple interpretation of source area and landslide boundary; (b)

284 landslide boundary inferred from InSAR coherence analysis; (c) actual landslide boundary from 285 UAV image. 
This paper has to be cited as: Dai K, Xu Q, Li Z, Tomás R, Fan X, Dong X, Li W, Zhou Z, Gou J and Ran P (2019) Post-disaster assessment of 2017 catastrophic xinmo landslide (china) by spaceborne sar interferometry. Landslides. doi: 10.1007/s10346-019-01152-4. The final publication is available at Elsevier via:

https://link.springer.com/article/10.1007/s10346-019-01152-4

\section{Landslide volume estimation and discussion}

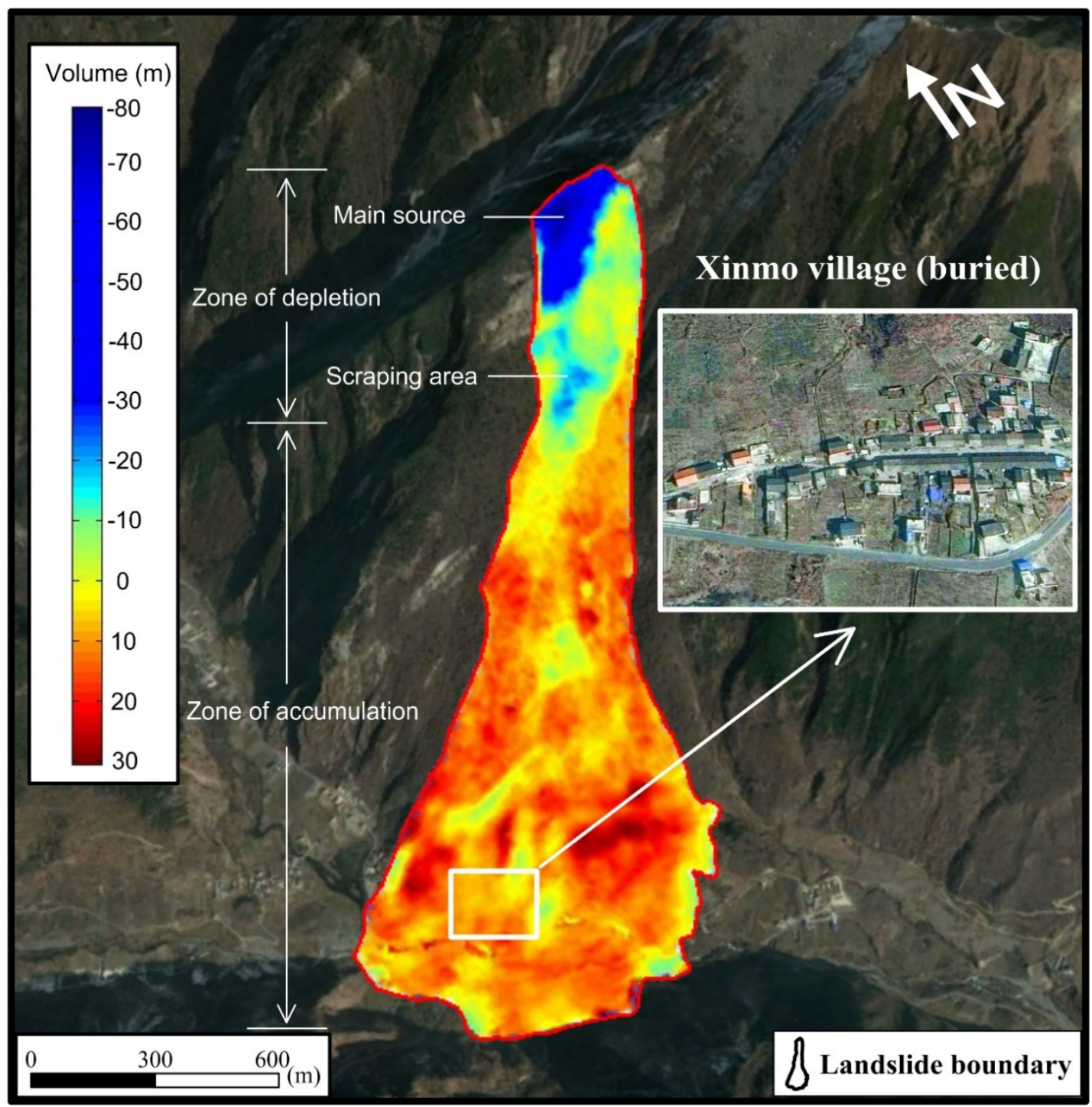

288 Fig. 8 Elevation change map of Xinmo landslide derived from the pre-failure TanDEM-X DEM

289 and the post-failure UAV DEM. Positive and negative values mean the accumulation volume

290 and depletion volume, respectively.

291 Comparing the pre-failure TanDEM-X DEM and post-failure UAV DEM, the elevation

292 change map of Xinmo landslide was calculated (Fig. 8). The areas with negative volume

293 were regarded as the zone of depletion, which can be subdivided into two parts. The

294 first part was the main source of this landslide, located in the top of the slope with a

295 maximum depth of $80 \mathrm{~m}$. Below the main source, there was a scraping area as a part of

296 the zone of depletion with a maximum depth of $24 \mathrm{~m}$. Based on the elevation change 
This paper has to be cited as: Dai K, Xu Q, Li Z, Tomás R, Fan X, Dong X, Li W, Zhou Z, Gou J and Ran P (2019) Post-disaster assessment of 2017 catastrophic xinmo landslide (china) by spaceborne sar interferometry. Landslides. doi: 10.1007/s10346-019-01152-4. The final publication is available at Elsevier via: https://link.springer.com/article/10.1007/s10346-019-01152-4

map, the total volume of depletion area was estimated to $4.26 \times 10^{6} \mathrm{~m}^{3}$. The areas with positive volume were regarded as the accumulation zone, and the total accumulation volume was estimated to $13.25 \times 10^{6}$. The thickest part was in the right of the accumulation body with a maximum thickness of about $30 \mathrm{~m}$. The Xinmo village was fully buried by the deposition with an average thick of $10 \mathrm{~m}$.

It is worth mentioning that for areas with a slope greater than $20 \%$, TanDEM-X DEM have a relative vertical accuracy of $4 \mathrm{~m}$ (eoPortal Directory 2014), and the accuracy of UAV DEM was estimated to $4 \mathrm{~m}$. Therefore, according to the law of error propagation, the final depletion volume and accumulation volume were estimated to $4.26 \pm 0.12 \times 10^{6}$ and $13.25 \pm 0.56 \times 10^{6}$, respectively.

The calculated volumes suggest that the source area was relative small compared to the accumulated deposits. In fact, it is known that when a rockslide mass disintegrates and fragments in the process of becoming a rock avalanche, an initial volume increase ranging from 7 to $26 \%$ occurs (Hungr and Evans 2004). In Xinmo landslide the volume of loose soils placed in the accumulation zone is about three times larger (i.e. higher than $300 \%$ ) than the depletion volume. The reason for this additional volume increase is that the high kinematic energy reached by the slid mass during the event struck, entrained and remobilized the old landslide deposits located in the middle and lower parts of the Xinmo slope increasing the volume of mobilized loose material (Bai et al. 2018, Fan et al, 2017b, Hu et al. 2018, Ouyang et al. 2017, Pei et al. 2018, Su et al. 2017, Wang et al. 2018, Zhao et al. 2018)

After the Xinmo landslide, several organizations and researches estimated the volume of the landslide with different methods. The details of their methods and the estimated volume results are shown in Table 2. About 10 hours after the Xinmo landslides, Land and Resources Department of Sichuan Province on behalf of the government stated that the accumulation volume of this landslide reached up to 18 million $\mathrm{m}^{3}$ (The central people's government of China, 2017), which was estimated according to the preliminary estimation by the experts. Two months later, Fan et al. (2017a) revealed that the accumulation volume was $7.7 \pm 1.46 \times 10^{6}$ by comparing the pre-failure DEM acquired by aerial photogrammetry in 2013 and the post-DEM derived from UAV-1 data. Ouyang et al. (2017) estimated the volume of depletion area with the topographic map and UAV- 
This paper has to be cited as: Dai K, Xu Q, Li Z, Tomás R, Fan X, Dong X, Li W, Zhou Z, Gou J and Ran P (2019) Post-disaster assessment of 2017 catastrophic xinmo landslide (china) by spaceborne sar interferometry. Landslides. doi: 10.1007/s10346-019-01152-4. The final publication is available at Elsevier via: https://link.springer.com/article/10.1007/s10346-019-01152-4

2 data, revealing that the total depletion volume (including the entrained superficial mass in the track) was $5.08 \times 10^{6} \mathrm{~m}^{3}$. With the same data as Ouyang et al. (2017), Bai et al. (2018) estimated the depletion volume (including the erosion and sliding areas) and accumulation area as $6.3 \times 10^{6} \mathrm{~m}^{3}$ and $6.4 \times 10^{6} \mathrm{~m}^{3}$. By using the average thickness and coverage information, Fan et al. (2017b) estimated both the depletion volume and accumulation volume (including the accumulations in the track), which were estimated to be $4.3 \times 10^{6} \mathrm{~m}^{3}$ and quantified in about $13 \pm 1$ million $\mathrm{m}^{3}$, respectively. Wang et al. 2017, Su et al. 2017, Hu et al. 2018, Zhao et al. 2018, Pei et al. 2018 estimated the volume of this landslide successively. Unfortunately, the details of the calculation of volumes were not explained. All of the mentioned work were listed in the Table 2.

Compared with these previous work, the SAR image used to acquire the DEM was acquired on 07 February 2017 (4 months before the landslide), which has much better timeliness than the previous work. Both of the depletion volume and accumulation volume were accurately estimated from each pixel, guaranteeing the reliability of our results, which is consistent with the result from Fan et al. (2017b). The advanced TerraSAR-X/TanDEM-X satellite, which was designed to estimate the height of earth surface, provides us a space-based remote sensing way to acquire the accurate prefailure DEM.

Table 2 The depletion and accumulation volumes estimated by other researches and their data source

\begin{tabular}{|c|c|c|c|}
\hline References & $\begin{array}{c}\text { Depletion } \\
\text { volume }\left(\mathrm{m}^{3}\right)\end{array}$ & $\begin{array}{l}\text { Accumulation } \\
\text { volume }\left(\mathrm{m}^{3}\right)\end{array}$ & Data source ${ }^{[\mathrm{a}]}$ and vertical accuracy \\
\hline $\begin{array}{l}\text { Government } \\
\text { department }^{[\mathrm{b}]}\end{array}$ & 1 & $18 \times 10^{6}$ & Preliminary estimation by experts \\
\hline Fan et al. (2017a) & 1 & $7.7 \pm 1.46 \times 10^{6}$ & $\begin{array}{l}\text { Pre: from aerial photo in } 2013(3 \mathrm{~m}) \\
\text { Post: from UAV-1 }{ }^{[\mathrm{c}]}(3 \mathrm{~m})\end{array}$ \\
\hline Ouyang et al. (2017) & $5.08 \times 10^{6}$ & 1 & $\begin{array}{l}\text { Pre: topographic map } \\
\text { Post: from UAV-2 } 2^{[\mathrm{d}]}\end{array}$ \\
\hline Fan et al. (2017b) & $4.3 \times 10^{6}$ & $13 \pm 1 \times 10^{6}$ & $\begin{array}{l}\text { Pre:1:10000 topographic map }{ }^{[\mathrm{e}]} \\
\text { Post: from UAV-3 }{ }^{[\mathrm{f}]}\end{array}$ \\
\hline
\end{tabular}


This paper has to be cited as: Dai K, Xu Q, Li Z, Tomás R, Fan X, Dong X, Li W, Zhou Z, Gou J and Ran P (2019) Post-disaster assessment of 2017 catastrophic xinmo landslide (china) by spaceborne sar interferometry. Landslides. doi: 10.1007/s10346-019-01152-4. The final publication is available at Elsevier via: https://ink.springer.com/article/10.1007/s10346-019-01152-4

\begin{tabular}{|c|c|c|c|}
\hline Wang et al. (2017) & $5.2 \times 10^{6}$ & $18.0 \times 10^{6}$ & $\begin{array}{c}\text { Based on field investigation and } \\
\text { DEM comparison. }\end{array}$ \\
\hline Su et al. (2017) & $3.0 \times 10^{6}$ & $8.0 \times 10^{6}$ & DTM comparison without details \\
\hline \multirow[t]{2}{*}{ Bai et al. (2018) } & \multirow[t]{2}{*}{$6.3 \times 10^{6}$} & \multirow[t]{2}{*}{$6.4 \times 10^{6}$} & \\
\hline & & & Post: from UAV-2 \\
\hline Hu et al. (2018) & $3.0 \times 10^{6}$ & $10.0 \times 10^{6}$ & Not specified \\
\hline Zhao et al. (2018) & $4.46 \times 10^{6}$ & 1 & Not specified \\
\hline Pei et al. (2018) & $4.3 \times 10^{6}$ & $13 \times 10^{6}$ & DEM comparison without details. \\
\hline \multirow[t]{2}{*}{ This study } & $4.26 \pm 0.12 \times$ & $13.25 \pm 0.56 \times$ & Pre: from TanDEM-X (4m) \\
\hline & $10^{6}$ & $10^{6}$ & Post: from UAV-3 (4m) \\
\hline
\end{tabular}

348 Note: [a] Pre-failure DEM (Pre) and Post-failure DEM (Post). [b] Released by Land and 349 Resources Department of Sichuan Province (The central people's government of China 350 2017). [c] UAV-1 data was acquired on 25 June by Sichuan Bureau of Surveying, Mapping and 351 Geo-information. [d] UAV-2 was performed by the Sichuan Geomatics Center. [e] The map was 352 prepared using stereo images of Cartosat-1 (2.5 m resolution) recorded in 2006 and of Pleiades $353(0.7 \mathrm{~m})$ recorded in 2013. [f] UAV3 data was acquired on June $26^{\text {th }}, 2017$ with the use of a 354 F1000 UAV by SKLGP.

\section{6. Conclusion}

356 In this paper, we illustrate a methodology to perform post-disaster assessment with 357 spaceborne SAR data, instead of field investigation or conventional optical remote 358 sensing. By means of the coherence analysis we proposed, the landslide source area and 359 boundaries could be identified with Sentinel-1 satellite data. Compared with UAV 360 interpretation, the result is efficient and reliable under tough cloud weather and steep 361 terrain condition, which increases the personnel safety and efficiency for prompt post362 disaster assessment.

363 The advanced TerraSAR-X/TanDEM-X satellite was designed to acquire the accurate 364 DEM, which provides us a space-based remote sensing way to acquire pre-failure DEM 365 covering landslide site. The SAR data acquired on 07 February 2017 was used to derive 366 the pre-failure DEM in this study, which was the up-to-date accurate DEM before the 
This paper has to be cited as: Dai K, Xu Q, Li Z, Tomás R, Fan X, Dong X, Li W, Zhou Z, Gou J and Ran P (2019) Post-disaster assessment of 2017 catastrophic xinmo landslide (china) by spaceborne sar interferometry. Landslides. doi: 10.1007/s10346-019-01152-4. The final publication is available at Elsevier via: https://link.springer.com/article/10.1007/s10346-019-01152-4

landslide, which means it would have better accuracy than the DEM derived from topographic map or aerial photo several years ago. With the TanDEM-X pre-failure DEM and post-failure DEM, the elevation variations map was derived, in which the mean source, scraping area and accumulation area can be clearly identified. The volume of the depletion volume and accumulation volume were estimated as $4.26 \pm 0.12 \times 10^{6}$ and $13.25 \pm 0.56 \times 10^{6}$, respectively, which is consistent with the latest published work (Fan et al. 2017b).

Therefore, it was proved that spaceborne SAR could provide us a new space-based remote sensing way to assess landslide disasters. As an alternative and effective method, spaceborne SAR interferometry has the potential of playing an important role in the post-disaster assessment in the future.

\section{Acknowledgement}

This work was funded by Sichuan Science and Technology Plan Key Research and Development Program (Grant No. 2018SZ0339), National Natural Science Foundation of China (Grant No. 41801391), State Key Laboratory of Geodesy and Earth's Dynamics Open fund (Grant No. SKLGED2018-5-3-E), The Funds for Creative Research Groups of China (Grant No. 41521002) and partially supported by the Spanish Ministry of Economy, Industry and Competitiveness (MINECO), the State Agency of Research (AEI) and European Funds for Regional Development (FEDER), under project TIN2014-55413-C2-2-P and by the Spanish Ministry of Education, Culture and Sport, under project PRX17/00439. This work was also supported by the National Environment Research Council (NERC) through the Centre for the Observation and Modelling of Earthquakes, Volcanoes and Tectonics (COMET, ref.: come30001), the LiCS project (ref. NE/K010794/1), the ESA-MOST DRAGON-4 project (ref. 32244), and the Hunan Province Key Laboratory of Coal Resources Clean-Utilization and Mine Environment Protection, Hunan University of Science and Technology (Ref. E21608).

\section{Reference}

Andersson-Sköld Y, Bergman R, Johansson M, Persson E and Nyberg L (2013) Landslide risk management - a brief overview and example from sweden of current situation and climate change. International Journal of Disaster Risk Reduction 3: 4461. doi: https://doi.org/10.1016/j.ijdrr.2012.11.002 
This paper has to be cited as: Dai K, Xu Q, Li Z, Tomás R, Fan X, Dong X, Li W, Zhou Z, Gou J and Ran P (2019) Post-disaster assessment of 2017 catastrophic xinmo landslide (china) by spaceborne sar interferometry. Landslides. doi: 10.1007/s10346-019-01152-4. The final publication is available at Elsevier via: https://link.springer.com/article/10.1007/s10346-019-01152-4

Bai X, Jian J, He S and Liu W (2018) Dynamic process of the massive xinmo landslide, sichuan (china), from joint seismic signal and morphodynamic analysis. Bulletin of Engineering Geology and the Environment: 1-11.

Cascini, L., Fornaro, G., \& Peduto, D. (2010). Advanced low-and full-resolution DInSAR map generation for slow-moving landslide analysis at different scales. Engineering Geology, 112(1-4), 29-42.

Chen M, Tomás R, Li Z, Motagh M, Li T, Hu L, Gong H, Li X, Yu J and Gong X (2016) Imaging land subsidence induced by groundwater extraction in beijing (china) using satellite radar interferometry. Remote Sensing 8: 468.

Cigna, F., Bianchini, S., \& Casagli, N. (2013). How to assess landslide activity and intensity with Persistent Scatterer Interferometry (PSI): the PSI-based matrix approach. Landslides, 10(3), 267-283.

COMET (2017) Sentinel-1 satellites reveal pre-event movements and source areas of the maoxian landslides, china. http://comet.nerc.ac.uk/sentinel-1-satellites-revealpre-event-movements-source-areas-maoxian-landslides-china/. Accessed 18 August 2018.

Dai FC, Lee CF and Ngai YY (2002) Landslide risk assessment and management: An overview. Engineering Geology 64: 65-87. doi: https://doi.org/10.1016/S00137952(01)00093-X

Dai K, Li Z, Tomás R, Liu G, Yu B, Wang X, Cheng H, Chen J and Stockamp J (2016) Monitoring activity at the daguangbao mega-landslide (china) using sentinel-1 tops time series interferometry. Remote Sensing of Environment 186: 501-513. doi: http://dx.doi.org/10.1016/j.rse.2016.09.009

Dai K, Liu G, Li Z, Li T, Yu B, Wang X and Singleton A (2015) Extracting vertical displacement rates in shanghai (china) with multi-platform sar images. Remote Sensing 7: 9542-9562. doi: 10.3390/rs70809542

Del Soldato, M., Riquelme, A., Bianchini, S., Tomàs, R., Di Martire, D., De Vita, P., ... \& Calcaterra, D. (2018). Multisource data integration to investigate one century of evolution for the Agnone landslide (Molise, southern Italy). Landslides, 15(11), 2113-2128.

DLR (2010) TanDEM-X - A New High Resolution Interferometric SAR Mission. http://www.dlr.de/hr/en/desktopdefault.aspx/tabid-2317/3669_read-5488/. Accessed 18 August 2018.

Dong J, Zhang L, Li M, Yu Y, Liao M, Gong J and Luo H (2017) Measuring precursory movements of the recent xinmo landslide in mao county, china with sentinel-1 and alos-2 palsar-2 datasets. Landslides: 1-10. 
This paper has to be cited as: Dai K, Xu Q, Li Z, Tomás R, Fan X, Dong X, Li W, Zhou Z, Gou J and Ran P (2019) Post-disaster assessment of 2017 catastrophic xinmo landslide (china) by spaceborne sar interferometry. Landslides. doi: 10.1007/s10346-019-01152-4. The final publication is available at Elsevier via: https://link.springer.com/article/10.1007/s10346-019-01152-4

Du Y, Xu Q, Zhang L, Feng G, Li Z, Chen R-F and Lin C-W (2017) Recent landslide movement in tsaoling, taiwan tracked by terrasar-x/tandem-x dem time series. Remote Sensing 9: 353.

eoPortal Directory (2014) TDX. https://directory.eoportal.org/web/eoportal/satellitemissions/t/tandem-x. Accessed 18 August 2018.

ESA (2014) Sentinel-1. https://sentinel.esa.int/web/sentinel/missions/sentinel-1. Accessed 18 August 2018

Fan J, Zhang X, Su F, Ge Y, Tarolli P, Yang Z, Zeng C and Zeng Z (2017a) Geometrical feature analysis and disaster assessment of the xinmo landslide based on remote sensing data. Journal of Mountain Science 14: 1677-1688.

Fan X, van Westen CJ, Korup O, Gorum T, Xu Q, Dai F, Huang R and Wang G (2012) Transient water and sediment storage of the decaying landslide dams induced by the 2008 wenchuan earthquake, china. Geomorphology 171: 58-68.

Fan X, Xu Q, Scaringi G, Dai L, Li W, Dong X, Zhu X, Pei X, Dai K and Havenith HB (2017b) Failure mechanism and kinematics of the deadly june 24th 2017 xinmo landslide, maoxian, sichuan, china. Landslides: 1-18.

Fernández, T., Pérez, J. L., Colomo, C., Cardenal, J., Delgado, J., Palenzuela, J. A., ... \& Chacón, J. (2017). Assessment of the evolution of a landslide using digital photogrammetry and LiDAR techniques in the Alpujarras region (Granada, southeastern Spain). Geosciences, 7(2), 32.

Ferretti, A., Prati, C., \& Rocca, F. (1999). Multibaseline InSAR DEM reconstruction: The wavelet approach. IEEE Transactions on Geoscience and Remote Sensing, 37(2), 705-715.

Fiorucci F, Cardinali M, Carlà R, Rossi M, Mondini AC, Santurri L, Ardizzone F and Guzzetti F (2011) Seasonal landslide mapping and estimation of landslide mobilization rates using aerial and satellite images. Geomorphology 129: 59-70. doi: https://doi.org/10.1016/j.geomorph.2011.01.013

Frattini P, Crosta GB, Rossini M and Allievi J (2018) Activity and kinematic behaviour of deep-seated landslides from ps-insar displacement rate measurements. Landslides: $1-18$.

Gao X, Liu Y, Li T and Wu D (2017) High precision dem generation algorithm based on insar multi-look iteration. Remote Sensing 9: 741.

Ge L, Ng AH-M, Li X, Abidin HZ and Gumilar I (2014) Land subsidence characteristics of bandung basin as revealed by envisat asar and alos palsar interferometry. Remote Sensing of Environment 154: 46-60. doi: 10.1016/j.rse.2014.08.004 
This paper has to be cited as: Dai K, Xu Q, Li Z, Tomás R, Fan X, Dong X, Li W, Zhou Z, Gou J and Ran P (2019) Post-disaster assessment of 2017 catastrophic xinmo landslide (china) by spaceborne sar interferometry. Landslides. doi: 10.1007/s10346-019-01152-4. The final publication is available at Elsevier via: https://link.springer.com/article/10.1007/s10346-019-01152-4

Guzzetti F, Carrara A, Cardinali M and Reichenbach P (1999) Landslide hazard evaluation: A review of current techniques and their application in a multi-scale study, central italy. Geomorphology 31: 181-216. doi: https://doi.org/10.1016/S0169555X(99)00078-1

Hanssen RF (2000) Radar interferometry - data interpretation and error analysis.

Hu K, Wu C, Tang J, Pasuto A, Li Y and Yan S (2018) New understandings of the june 24th 2017 xinmo landslide, maoxian, sichuan, china. Landslides 15: 2465-2474. doi: $10.1007 / \mathrm{s} 10346-018-1073-2$

Hungr O and Evans SG (2004) Entrainment of debris in rock avalanches: An analysis of a long run-out mechanism. GSA Bulletin 116: 1240-1252. doi: 10.1130/B25362.1

Intrieri E, Raspini F, Fumagalli A, Lu P, Del Conte S, Farina P, Allievi J, Ferretti A and Casagli N (2017) The maoxian landslide as seen from space: Detecting precursors of failure with sentinel-1 data. Landslides. doi: 10.1007/s10346-017-0915-7

Jiang H, Mao X, Xu H, Yang H, Ma X, Zhong N and Li Y (2014) Provenance and earthquake signature of the last deglacial xinmocun lacustrine sediments at diexi, east tibet. Geomorphology 204: 518-531.

Lucieer, A., Jong, S. M. D., \& Turner, D. (2014). Mapping landslide displacements using Structure from Motion (SfM) and image correlation of multi-temporal UAV photography. Progress in Physical Geography, 38(1), 97-116.

Meng, W., Xu, Y., Cheng, W. C., \& Arulrajah, A. (2018). Landslide Event on 24 June in Sichuan Province, China: Preliminary Investigation and Analysis. Geosciences, $8(2), 39$.

Miller, M., \& Shirzaei, M. (2015). Spatiotemporal characterization of land subsidence and uplift in Phoenix using InSAR time series and wavelet transforms. Journal of Geophysical Research: Solid Earth, 120(8), 5822-5842.

Neelmeijer, J., Motagh, M., \& Bookhagen, B. (2017). High-resolution digital elevation models from single-pass TanDEM-X interferometry over mountainous regions: A case study of Inylchek Glacier, Central Asia. ISPRS Journal of Photogrammetry and Remote Sensing, 130, 108-121.

Ouyang C, Zhao W, He S, Wang D, Zhou S, An H, Wang Z and Cheng D (2017) Numerical modeling and dynamic analysis of the 2017 xinmo landslide in maoxian county, china. Journal of Mountain Science 14: 1701-1711.

Pei X, Guo B, Cui S, Wang D, Xu Q and Li T (2018) On the initiation, movement and deposition of a large landslide in maoxian county, china. Journal of Mountain Science: $1-12$.

Qiu J, Wang X, He S, Liu H, Lai J and Wang L (2017) The catastrophic landside in 
This paper has to be cited as: Dai K, Xu Q, Li Z, Tomás R, Fan X, Dong X, Li W, Zhou Z, Gou J and Ran P (2019) Post-disaster assessment of 2017 catastrophic xinmo landslide (china) by spaceborne sar interferometry. Landslides. doi: 10.1007/s10346-019-01152-4. The final publication is available at Elsevier via: https://ink.springer.com/article/10.1007/s10346-019-01152-4

maoxian county, sichuan, sw china, on june 24, 2017. Natural Hazards 89: 14851493. doi: 10.1007/s11069-017-3026-9

Qu T, Lu P, Liu C, Wu H, Shao X, Wan H, Li N and Li R (2016) Hybrid-sar technique: Joint analysis using phase-based and amplitude-based methods for the xishancun giant landslide monitoring. Remote Sensing 8: 874.

Raspini, F., Ciampalini, A., Del Conte, S., Lombardi, L., Nocentini, M., Gigli, G., ... \& Casagli, N. (2015). Exploitation of amplitude and phase of satellite SAR images for landslide mapping: the case of Montescaglioso (South Italy). Remote Sensing, 7(11), 14576-14596.

Rossi, G., Tanteri, L., Tofani, V., Vannocci, P., Moretti, S., \& Casagli, N. (2018). Multitemporal UAV surveys for landslide mapping and characterization. Landslides, $1-8$.

Scaringi G, Fan X, Xu Q, Liu C, Ouyang C, Domènech G, Yang F and Dai L (2018) Some considerations on the use of numerical methods to simulate past landslides and possible new failures: The case of the recent xinmo landslide (sichuan, china). Landslides: 1-17.

Shi X, Zhang L, Zhou C, Li M and Liao M (2018) Retrieval of time series threedimensional landslide surface displacements from multi-angular sar observations. Landslides: 1-13.

Su L, Hu K, Zhang W, Wang J, Lei Y, Zhang C, Cui P, Pasuto A and Zheng Q (2017) Characteristics and triggering mechanism of xinmo landslide on 24 june 2017 in sichuan, china. Journal of Mountain Science 14: 1689-1700. doi: 10.1007/s11629017-4609-3

The central people's government of China (2017) The volume of landslides in Mao County,Sichuan Province reached 18 million cubic meters with a maximum drop of 1600 meters. http://www.gov.cn/xinwen/2017-06/24/content_5205161.htm. Accessed 18 August 2018.

Tomás R, Li Z, Lopez-Sanchez JM, Liu P and Singleton A (2015) Using wavelet tools to analyse seasonal variations from insar time-series data: A case study of the huangtupo landslide. Landslides. doi: 10.1007/s10346-015-0589-y

Tsai F, Hwang J, Chen L and Lin T (2010) Post-disaster assessment of landslides in southern taiwan after 2009 typhoon morakot using remote sensing and spatial analysis. Natural Hazards and Earth System Sciences 10: 2179.

Van der Horst, T., Rutten, M. M., van de Giesen, N. C., \& Hanssen, R. F. (2018). Monitoring land subsidence in Yangon, Myanmar using Sentinel-1 persistent scatterer interferometry and assessment of driving mechanisms. Remote sensing of 
This paper has to be cited as: Dai K, Xu Q, Li Z, Tomás R, Fan X, Dong X, Li W, Zhou Z, Gou J and Ran P (2019) Post-disaster assessment of 2017 catastrophic xinmo landslide (china) by spaceborne sar interferometry. Landslides. doi: 10.1007/s10346-019-01152-4. The final publication is available at Elsevier via: https://ink.springer.com/article/10.1007/s10346-019-01152-4

542

environment, 217, 101-110.

Wang Y, Zhao B and Li J (2017) Mechanism of the catastrophic june 2017 landslide at xinmo village, songping river, sichuan province, china. Landslides: 1-13.

Zhao S, Chigira M and Wu X (2018) Buckling deformations at the 2017 xinmo landslide site and nearby slopes, maoxian, sichuan, china. Engineering Geology 246: 187-197. doi: https://doi.org/10.1016/j.enggeo.2018.09.033 